\title{
Radiation Resistant Insulation Systems for the ITER Toroidal Field Coils
}

\author{
R. Prokopec ${ }^{1, *}$, K. Humer ${ }^{1}$, R. K. Maix ${ }^{1}$, H. Fillunger ${ }^{1}$, H. W. Weber ${ }^{1}$, J. Knaster ${ }^{2}$, F. Savary ${ }^{2}$ \\ ${ }^{1}$ Vienna University of Technology, Atominstitut, Austria \\ ${ }^{2}$ ITER Organization, Saint Paul Lez Durance, France
}

Copyright $(\subset 2015$ by authors, all rights reserved. Authors agree that this article remains permanently open access under the terms of the Creative Commons Attribution License 4.0 International License

\begin{abstract}
Insulation systems for fusion magnets have to operate under intense radiation, mainly fast neutrons and $\gamma$-radiation. At the ITER design fluence of $1 \times 10^{22} \mathrm{~m}^{-2}(\mathrm{E}>0.1$ $\mathrm{MeV}$ ), conventional epoxy resins, which were used, e.g., for the ITER TF model coil, start to disintegrate. As a consequence, research programs were launched under EFDA, F4E and ITER contracts in order to find radiation harder resins as well as to investigate the properties of cyanate esters (CE) and CE/epoxy blends. The CE content was varied in the range between $100 \%$ and $20 \%$. Test materials, consisting of wrapped R-glass fiber / polyimide tapes and VPI impregnated with various resins, were produced by European industry and tested at $77 \mathrm{~K}$. Tensile and short beam shear tests were carried out to characterize the mechanical properties prior to and after irradiation to fast neutron fluences of up to $5 \times 10^{22} \mathrm{~m}^{-2}(\mathrm{E}>0.1 \mathrm{MeV})$ in the TRIGA reactor (Vienna). In addition, tension-tension fatigue measurements were performed in the load-controlled mode to simulate the pulsed operation conditions of ITER. It turned out that these CE based insulation systems offer excellent properties at the ITER design fluence including an adequate safety margin, especially when a mixing ratio of $40 \% \mathrm{CE}$ and $60 \%$ epoxy resin is employed. Slight modifications of the resin, mainly regarding an extension of the pot-life to more than 100 hours, were made in view of the dimensions and the complexity of the ITER TF coils. The corresponding results confirm their excellent performance and will be reported. Radiation resistant materials have also been developed by US and Japanese Industry. The qualification of these insulation systems is currently under way and comprises 40:60 CE / epoxy blends from different suppliers (Huntsman, CTD). Test materials were fabricated under the same conditions in order to provide a comparable data base. The results will be presented and discussed.
\end{abstract}

Keywords Superconducting Fusion Magnets, Magnet Insulation, Radiation Effects, Neutron Irradiation, Cyanate Ester - Epoxy Mixtures, Mechanical Properties

\section{Introduction}

Insulation systems for fusion magnets have to operate under intense radiation, mainly fast neutrons and $\gamma$-radiation. The fusion reaction produces high energy neutrons (14 MeV), which interact with the surrounding materials. Due to collisions the neutrons are slowed down and only a small fraction still has $\sim 14 \mathrm{MeV}$ when hitting the magnet coils. At this position the energy spectrum of the neutrons becomes similar to the fission spectrum of a reactor, which makes the simulation of radiation effects on the magnet coil insulation in a fission reactor possible. $i$

The ITER design fluence of fast neutrons $(\mathrm{E}>0.1 \mathrm{MeV})$ is $1 \times 10^{22} \mathrm{~m}^{-2}$ at the location of the TF magnets. At this fluence level, conventional epoxy resins used, e.g., for the ITER TF model coil, start to disintegrate. Both DGEBA based insulation systems fabricated by Ansaldo (Italy) and Alstom-MSA (France) showed significant radiation induced damage, especially under interlaminar shear load [1-3]. Reductions of the interlaminar shear strength by up to $50 \%$ were found. In addition, in some cases an adhesive was used to fix the polyimide foil to the glass fiber tape, which led to the formation of bubbles after irradiation and further degradation. As a consequence, research programs were launched under EFDA, F4E and ITER contracts, in order to find radiation harder resins as well as to investigate the properties of cyanate esters (CE) and CE/epoxy blends [4-6]. CEs offer enhanced temperature and radiation resistance as well as high mechanical strength, but they had hardly been used by magnet industry so far. CEs are also compatible with the VPI process foreseen for ITER.

Test materials were produced with R-glass fiber / polyimide tapes wrapped half overlapped around an aluminium plate and VPI impregnated with pure $\mathrm{CE}$ and various mixtures of CE/epoxy resins and an additional $\mathrm{Mn}$ catalyst supplied by Huntsman, Switzerland. All materials were characterized under static and dynamic tensile and under static interlaminar shear load at $77 \mathrm{~K}$ prior to and after irradiation to fast neutron fluences of up to $5 \times 10^{22} \mathrm{~m}^{-2}(\mathrm{E}>0.1$ $\mathrm{MeV})$. The results will be presented in section 3.1 . 
Besides these European activities, considerable progress with developing radiation hard $\mathrm{CE}$ based insulation systems was also achieved by US industry, i.e. CTD, Boulder, USA, and Japanese industry, i.e. Toshiba, Japan [7]. Unfortunately, the results were not directly comparable due to differences in the material composition, such as the type of glass fibers, the type of reinforcement, the glass fiber content, the type of polyimide film, the mixture of the blend, etc. Therefore, a qualification program of the TF insulation system was launched in March 2009. Based on the ITER specification of the TF coil insulation, two CE blends were supplied by Huntsman, Switzerland, and Composite Technology Development (CTD), USA, in order to be qualified for ITER. In both cases, the resin system is a mixture of $40 \% \mathrm{CE}$ and $60 \%$ epoxy with an admixed Co-catalyst. By exchanging the Mn catalyst originally used by a Co-catalyst, the pot-life requirement of more than 100 hours was reached, which will offer sufficient time for impregnating the complex TF coil structure.

Comparable insulation samples were manufactured by Marti-Supratec, Switzerland, with exactly the same reinforcement and fabrication procedure, in order to check for the best radiation hardness and mechanical material performance. The materials were characterized under tensile and interlaminar shear load at $77 \mathrm{~K}$ prior to and after irradiation to a fast neutron fluence of $2 \times 10^{22} \mathrm{~m}^{-2}$. Tension-tension fatigue measurements were performed in order to simulate the pulsed operation conditions of ITER.

\section{Materials and Test Procedures}

Several materials were fabricated using the vacuum pressure impregnation (VPI) technique. The reinforcement consists of one R-glass fiber layer $(0.25 \times 40 \mathrm{~mm})$ and seven layers of glass fiber / Kapton $200 \mathrm{HN}$ tape $(0.05 \times 36 \mathrm{~mm})$ sandwiches wrapped half-overlapped around an aluminium plate as would be done for insulating the ITER TF coils. The wrapped plates were dried under vacuum at $\sim 100^{\circ} \mathrm{C}$ to remove moisture, which may be absorbed during storing and wrapping. Afterwards they were impregnated with the resin employing the curing cycle recommended by the resin supplier.

All static and dynamic tests were carried out at $77 \mathrm{~K}$ using a servo-hydraulic MTS 810 test device, which was modified for measurements in a liquid nitrogen environment. The ultimate tensile strength (UTS) was measured according to the DIN 53455 and the ASTM D638 standards. Dog-bone shaped samples of $70 \mathrm{~mm}$ length were cut from the sample plates. This reduced size is necessary for carrying out the irradiation experiments in a reasonable way [8].

The apparent interlaminar shear strength (ILSS) was assessed by the short-beam-shear (SBS) test according to the ASTM D2344 standard (23 × $6.4 \times 4 \mathrm{~mm}^{3}$ sample size $)$. Span-to-thickness ratios between $4: 1$ and 5:1 were used, in order to obtain interlaminar fracture. For the simulation of the pulsed ITER operation, tension-tension fatigue measurements (ASTM D3479) were done at a frequency of $10 \mathrm{~Hz}$ applying a sinusoidal load function up to $10^{6}$ cycles at minimum-to-peak stress ratios (R-ratio) of 0.1. Each data point refers to 4 or more samples.

The materials have anisotropic properties because of the manufacturing process. Therefore, test specimens were cut parallel $\left(0^{\circ}\right)$ and perpendicular $\left(90^{\circ}\right)$ to the winding direction of the reinforcing glass fiber tapes. For tensile tests only the $90^{\circ}$ direction was investigated, because the UTS in $0^{\circ}$ direction is mostly dominated by the strength of the glass fibers and the influence of the irradiation is much smaller than for $90^{\circ}$ samples.

The neutron irradiation was performed in the TRIGA reactor (Vienna) at ambient temperature $(\sim 340 \mathrm{~K})$ to fast neutron fluences of $1,2,4$, and $5 \times 10^{22} \mathrm{~m}^{-2}(\mathrm{E}>0.1 \mathrm{MeV})$ respectively, which corresponds to a total absorbed dose of up to 250 MGy [9].

\section{Results}

\subsection{Investigations of the CE Content}

This section reports on the influence of the CE content on the mechanical properties and on the radiation resistance. The CE content was reduced from $100 \%$ down to $20 \%$. A summary of the resins and their curing procedures is presented in Table 1. The numbers in brackets denote the CE content.

In the unirradiated state, both the UTS and the ILSS is highest for the system containing $40 \%$ CE. This is in good agreement with expectations expressed by the resin supplier, who pointed out that from a chemical point of view the best mechanical properties should be reached at $40 \% \mathrm{CE}$. However, the differences between the investigated materials are small. The UTS is mainly in the range from 250 to 270 MPa except for T2 (40) (cf. Table 2). The ILSS in $0^{\circ}$ direction lies between 60 and $80 \mathrm{MPa}$, whereas in $90^{\circ}$ direction the ILSS is lower by approximately 10 to $15 \mathrm{MPa}$ (cf. Table 3). 
Table 1. OVERVIEW OF THE CE/EPOXY INSULATION SYSTEMS.

\begin{tabular}{|c|c|c|c|c|}
\hline Type & Cyanate ester & DGEBF epoxy & $\begin{array}{c}\text { Insulation } \\
\text { System }\end{array}$ & $\begin{array}{c}\text { CE/Epoxy } \\
\text { Ratio } \\
\end{array}$ \\
\hline & & & $\mathrm{T} 1(100)$ & 100:0 \\
\hline Resin & AroCy-L10 & PY306 & $\mathrm{T} 2(40)$ & $40: 60$ \\
\hline Hardener & --- & ---- & T8 (30) & $30: 70$ \\
\hline Additives & $\begin{array}{l}\text { Mn Acetylacetonate in } \\
\text { Nonylphenol }\end{array}$ & & T10 (20) & $20: 80$ \\
\hline Reinforcement & \multicolumn{2}{|c|}{ R-glass / polyimide } & & \\
\hline Curing Temp. & \multicolumn{2}{|c|}{$\begin{array}{l}4 \mathrm{~h} @ 100^{\circ} \mathrm{C} \\
5 \mathrm{~h} @ 160^{\circ} \mathrm{C}\end{array}$} & & \\
\hline
\end{tabular}

Table 2. ULTIMATE TENSILE STRENGTH (UTS) IN Mpa FOR 90 DIRECTION MEASURED AT 77 K BEFORE AND AFTER IRRADIATION TO FAST NEUTRON FLUENCES OF UP TO $5 \times 10^{22} \mathrm{M}^{-2}(\mathrm{E}>0.1 \mathrm{Mev})$.

\begin{tabular}{ccccc}
\hline Insulation system & T1 (100) & T2 (40) & T8 (30) & T10 (20) \\
\hline unirr. & $250 \pm 19$ & $313 \pm 18$ & $269 \pm 19$ & $265 \pm 16$ \\
$1 \times 10^{22} \mathrm{~m}^{-2}$ & $250 \pm 22$ & $296 \pm 10$ & $274 \pm 6$ & $243 \pm 12$ \\
$2 \times 10^{22} \mathrm{~m}^{-2}$ & $228 \pm 13$ & $253 \pm 16$ & $260 \pm 7$ & $218 \pm 8$ \\
$5 \times 10^{22} \mathrm{~m}^{-2}$ & $193 \pm 6$ & & &
\end{tabular}

After irradiation to $1 \times 10^{22} \mathrm{~m}^{-2}(\mathrm{E}>0.1 \mathrm{MeV})$, no reduction of the UTS is found. The differences lie within the standard deviation. Even a reduction of the CE content to $20 \%$ does not lead to a significant reduction of the UTS after irradiation (cf. $T a b .2)$. At twice the ITER fluence the UTS is reduced by approximately $5-20 \%$ depending on the material. In addition, the pure CE material was exposed to $5 \times 10^{22} \mathrm{~m}^{-2}(\mathrm{E}>0.1 \mathrm{MeV})$. Even at this fluence level, it maintained $75 \%$ of its mechanical strength compared to the unirradiated state.

Similar results were obtained on the SBS samples which were irradiated to fast neutron fluences of up to $5 \times 10^{22} \mathrm{~m}^{-2}(\mathrm{E}>0.1$ $\mathrm{MeV}$ ) (cf. Tab. 3). In good agreement with the tensile tests, the CE content only plays a minor with respect to the radiation resistance up to a fast neutron fluence of $2 \times 10^{22} \mathrm{~m}^{-2}(\mathrm{E}>0.1 \mathrm{MeV})$. In $0^{\circ}$ direction the ILSS is found to be in the range between $50 \mathrm{MPa}$ and $62 \mathrm{MPa}$, whereas in $90^{\circ}$ direction, the ILSS is lower by 5 to $10 \mathrm{MPa}$. After irradiation to $4 \times 10^{22} \mathrm{~m}^{-2}(\mathrm{E}>0.1 \mathrm{MeV}$ ), a remarkably high ILSS is observed for the materials with a CE content above $40 \%$, in the range of $\sim 50 \mathrm{MPa}$ and $\sim 40 \mathrm{MPa}$, respectively, depending on the load direction. This corresponds to a reduction of the ILSS by $\sim 30 \%$.

Similar results were obtained from the SBS samples which were irradiated to fast neutron fluences of up to $5 \times 10^{22} \mathrm{~m}^{-2}$ $(\mathrm{E}>0.1 \mathrm{MeV})(c f . T a b .3)$. In good agreement with the tensile tests, the CE content plays only a minor role regarding the radiation resistance up to a fast neutron fluence of $2 \times 10^{22} \mathrm{~m}^{-2}(\mathrm{E}>0.1 \mathrm{MeV})$. In $0^{\circ}$ direction the ILSS is found to be in the range between $50 \mathrm{MPa}$ and $62 \mathrm{MPa}$, whereas in $90^{\circ}$ direction, the ILSS is lower by 5 to $10 \mathrm{MPa}$. After irradiation to $4 \times 10^{22}$ $\mathrm{m}^{-2}(\mathrm{E}>0.1 \mathrm{MeV})$, a remarkably high ILSS is observed for the materials with a CE content above $40 \%$, in the range of $\sim 50$ $\mathrm{MPa}$ and $\sim 40 \mathrm{MPa}$, respectively, depending on the load direction. This corresponds to a reduction of the ILSS by $\sim 30 \%$.

Table 3. APPARENT INTERLAMINAR SHEAR STRENGTH (ILSS)IN MPa FOR BOTH DIRECTIONS MEASURED AT 77 K BEFORE AND AFTER IRRADIATION TO FAST NEUTRON FLUENCES OF UP TO $5 \times 10^{22} \mathrm{~m}^{-2}(\mathrm{E}>0.1 \mathrm{MeV})$.

\begin{tabular}{|c|c|c|c|c|c|c|c|c|}
\hline \multirow[t]{2}{*}{ Insulation system } & \multicolumn{2}{|c|}{$\mathrm{T} 1(100)$} & \multicolumn{2}{|c|}{$\mathrm{T} 2(40)$} & \multicolumn{2}{|c|}{ T8 (30) } & \multicolumn{2}{|c|}{$\mathrm{T} 10(20)$} \\
\hline & $0^{\circ}$ & $90^{\circ}$ & $0^{\circ}$ & $90^{\circ}$ & $0^{\circ}$ & $90^{\circ}$ & $0^{\circ}$ & $90^{\circ}$ \\
\hline unirr. & $59 \pm 8$ & $42 \pm 10$ & $77 \pm 4$ & $57 \pm 3$ & $74 \pm 4$ & $63 \pm 9$ & $62 \pm 6$ & $48 \pm 9$ \\
\hline $1 \times 10^{22} \mathrm{~m}^{-2}$ & $68 \pm 4$ & $48 \pm 5$ & $66 \pm 5$ & $58 \pm 3$ & $69 \pm 8$ & $58 \pm 7$ & $65 \pm 4$ & $48 \pm 5$ \\
\hline $2 \times 10^{22} \mathrm{~m}^{-2}$ & $50 \pm 2$ & $46 \pm 1$ & $61 \pm 2$ & $52 \pm 3$ & $62 \pm 3$ & $51 \pm 3$ & $53 \pm 6$ & $48 \pm 3$ \\
\hline $4 \times 10^{22} \mathrm{~m}^{-2}$ & $46 \pm 2$ & $37 \pm 2$ & $52 \pm 2$ & $45 \pm 6$ & $43 \pm 3$ & $37 \pm 5$ & $36 \pm 4$ & $26 \pm 4$ \\
\hline $5 \times 10^{22} \mathrm{~m}^{-2}$ & $48 \pm 8$ & $33 \pm 5$ & $50 \pm 4$ & $37 \pm 2$ & & & & \\
\hline
\end{tabular}

For the other two systems, T8 (30) and T10 (20), the ILSS in $90^{\circ}$ direction drops to $26 \mathrm{MPa}$ in the worst case. Further irradiation to $5 \times 10^{22} \mathrm{~m}^{-2}(\mathrm{E}>0.1 \mathrm{MeV})$ shows increased radiation damage with decreasing CE content. However, the ILSS of the pure CE system is still remarkably high at 48 and $33 \mathrm{MPa}$, respectively (cf. Fig. 1). 


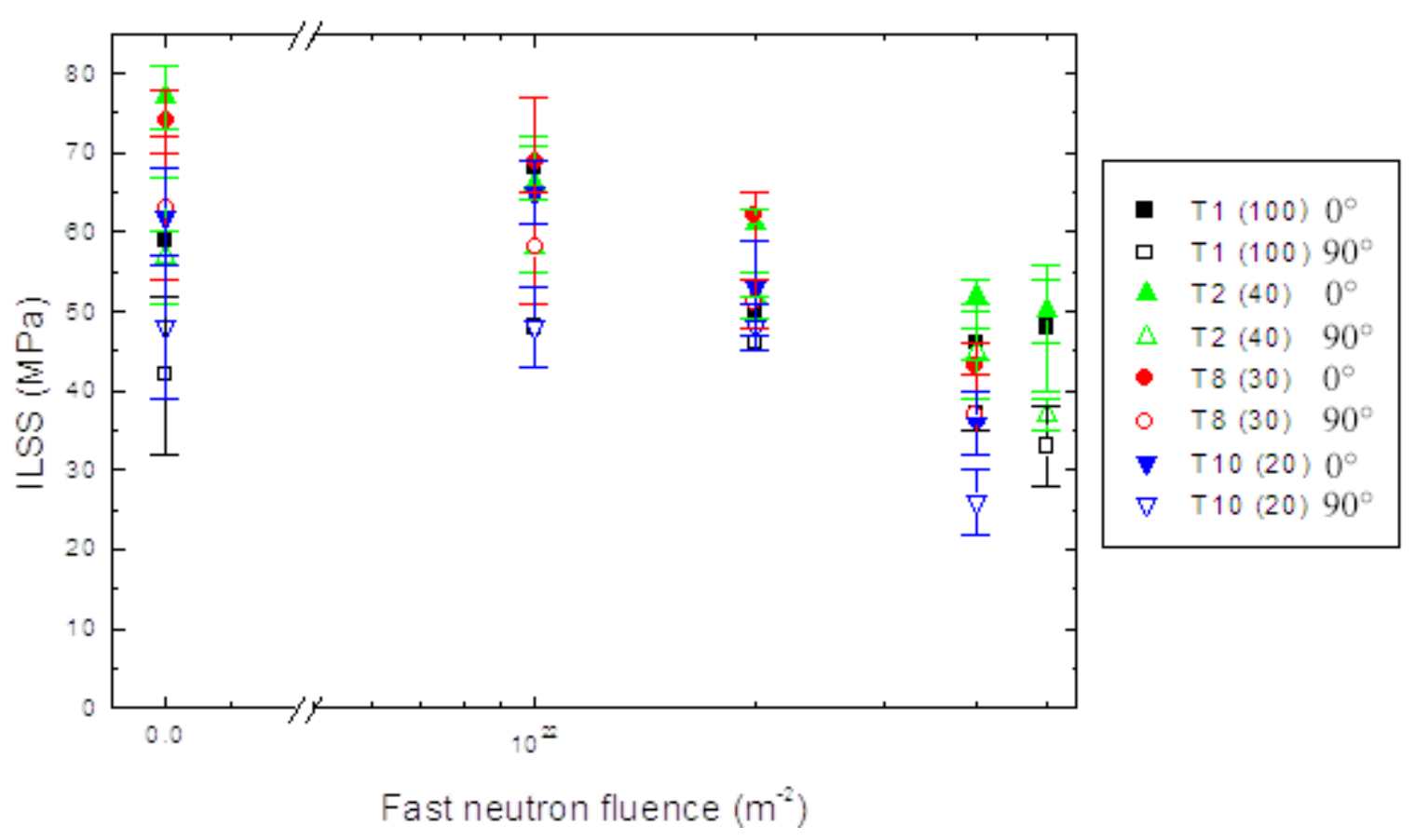

Figure 1. Apparent interlaminar shear strength (ILSS) for both directions measured at $77 \mathrm{~K}$ as a function of the fast neutron fluence.

\subsection{Qualification of the TF Coil Resins}

In this section, the results of two 40:60 CE/epoxy blends, which were qualified for ITER, are presented. Both materials are two component systems consisting of pure CE and epoxy resin, to which the catalyst is admixed. They also have an extended pot-life of more than 100 hours, which is necessary to ensure a proper impregnation of the large and complex TF coil structure. A summary of the materials and of their curing procedures is presented in Table 4 . In the following sections, only the abbreviations Huntsman and CTD will be used.

Table 4. Overview of the Resin Systems for the Tf Coil.

\begin{tabular}{ccc}
\hline Code & CTD 425 & $\begin{array}{c}\text { Huntsman } \\
\text { LMB6653/ } \\
\text { LMB6622-4 }\end{array}$ \\
\hline Impregnation temp. & $50{ }^{\circ} \mathrm{C}$ & $55^{\circ} \mathrm{C}$ \\
Jellification & $22 \mathrm{~h} @ 100{ }^{\circ} \mathrm{C}$ & $14 \mathrm{~h} @ 100{ }^{\circ} \mathrm{C}$ \\
Curing & $24 \mathrm{~h} @ 170^{\circ} \mathrm{C}$ & $18 \mathrm{~h} @ 155^{\circ} \mathrm{C}$ \\
\hline
\end{tabular}

\subsubsection{Tensile Properties}

In the unirradiated state, the UTS of Huntsman (309 MPa) and CTD (360 MPa) differs by about $15 \%$. Compared to the blends with the shorter pot-life (section 3.1), the UTS is the same or even higher, depending on the material. After irradiation to $2 \times 10^{22} \mathrm{~m}^{-2}(\mathrm{E}>0.1 \mathrm{MeV})$, their UTS is nearly identical. The UTS is slightly reduced to approximately 290 $\mathrm{MPa}$ for both materials, which corresponds to a degradation by $5 \%$ (Huntsman) and $20 \%$ (CTD), respectively. Table 5 summarizes the results on the UTS in their weakest direction $\left(90^{\circ}\right)$. The excellent material properties of the two blends are also shown under dynamic load. Fig. 2 shows the absolute and normalized stress-lifetime diagrams (S-N curves, Wöhler curves) obtained for $90^{\circ}$ loading before and after reactor irradiation to $2 \times 10^{22} \mathrm{~m}^{-2}(\mathrm{E}>0.1 \mathrm{MeV})$. The S-N curves show a continuous decrease up to $10^{6}$ load cycles prior to and after irradiation. No significant differences between the two materials are observed over a wide range apart from the slight variations at higher residual strengths for the unirradiated materials, as can be seen from the normalized curves. At the ITER point of 30000 load cycles, the residual strength is about $130 \mathrm{MPa}$, which is more than adequate. Beyond this point, the residual strength is less affected by irradiation.

\subsubsection{Apparent Interlaminar Shear Strength (ILSS)}

The results of the SBS tests before and after irradiation to $2 \times 10^{22} \mathrm{~m}^{-2}(\mathrm{E}>0.1 \mathrm{MeV})$ are presented in Table 5. In the unirradiated state, the ILSS is nearly the same and slightly above $70 \mathrm{MPa}$ for $0^{\circ}$ and slightly below $60 \mathrm{MPa}$ for $90^{\circ}$, i.e. the ILSS is smaller by about 20 to $25 \%$ compared to the $0^{\circ}$ direction. With respect to the previously tested CE/blends (section 3.1), it turns out that the minor modifications, which were necessary to extend the pot-life, do not reduce the mechanical strength. After irradiation to $2 \times 10^{22} \mathrm{~m}^{-2}$ ( $\mathrm{E}>0.1$ $\mathrm{MeV}$ ), the ILSS remains nearly unchanged for both materials in $0^{\circ}$ direction, and is slightly reduced by about $10 \%$ in $90^{\circ}$ direction to approximately $50 \mathrm{MPa}$, which also confirms the excellent radiation resistance of the materials at twice the ITER design fluence. 

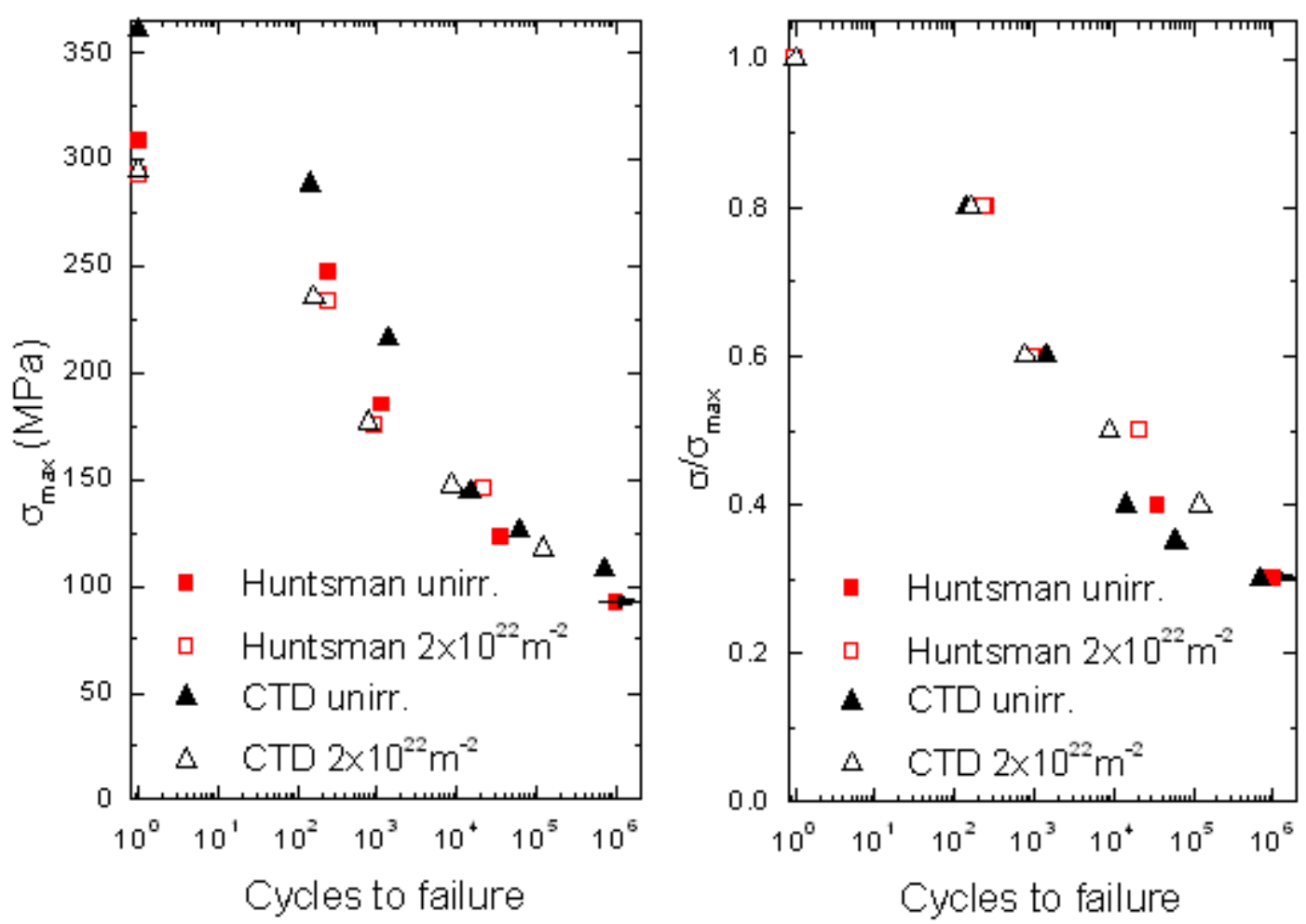

Figure 2. Absolute and normalized stress-lifetime diagrams of the Huntsman and CTD materials in $90^{\circ}$ direction measured at $77 \mathrm{~K}$ before and after irradiation to a fast neutron fluence of $2 \times 10^{22} \mathrm{~m}^{-2}(\mathrm{E}>0.1 \mathrm{MeV})$.

Table 5. ULTIMATE TENSILE STRENGTH (UTS)FOR $90^{\circ}$ DIRECTION AND APPARENT INTERLAMINAR SHEAR STRENGTH (ILSS) FOR BOTH DIRECTIONS MEASURED AT $77 \mathrm{~K}$ BEFORE AND AFTER IRRADIATION TO A FAST NEUTRONFLUENCE OF $2 \times 10^{22} \mathrm{~m}^{-2}(\mathrm{E}>0.1 \mathrm{MeV})$.

\begin{tabular}{|c|c|c|c|c|c|c|}
\hline \multirow[t]{2}{*}{ Material } & \multicolumn{2}{|c|}{ UTS $90^{\circ}$} & \multicolumn{2}{|c|}{ ILSS $0^{\circ}$} & \multicolumn{2}{|c|}{ ILSS $90^{\circ}$} \\
\hline & unirr. & irr. & unirr. & irr. & unirr. & irr. \\
\hline CTD & $360 \pm 5$ & $294 \pm 13$ & $71 \pm 3$ & $70 \pm 4$ & $58 \pm 6$ & $53 \pm 5$ \\
\hline Huntsman & $309 \pm 5$ & $292 \pm 13$ & $76 \pm 6$ & $72 \pm 4$ & $56 \pm 4$ & $51 \pm 4$ \\
\hline
\end{tabular}

\section{Summary}

The mechanical properties of various cyanate ester (CE) / epoxy blends were studied at $77 \mathrm{~K}$, in order to find radiation resistant materials for use as insulation systems for the ITER $\mathrm{TF}$ coils or for other superconducting coils exposed to radiation. In a first step the mixing ratio was varied in order find the best compromise with regarding their mechanical properties as well as costs. All the investigated materials were reactor irradiated to fast neutron fluences of up to $5 \times 10^{22} \mathrm{~m}^{-2}(\mathrm{E}>0.1 \mathrm{MeV})$. The results may be summarized as follows.

- The influence of the blend ratio on the mechanical properties is not very pronounced, the differences are only slightly above the standard deviation. The highest mechanical strength is obtained for a material, which contains $40 \% \mathrm{CE}$, both under tensile and interlaminar shear load.

- All investigated materials show excellent radiation resistance at the ITER level and twice the ITER fluence, i.e. $2 \times 10^{22} \mathrm{~m}^{-2}(\mathrm{E}>0.1 \mathrm{MeV})$. At higher fluence levels, materials with a lower $\mathrm{CE}$ content are more affected by irradiation. CE/epoxy blends with a CE content of more than $40 \%$ show an acceptable interlaminar shear strength even after irradiation to a fast neutron fluence of $5 \times 10^{22} \mathrm{~m}^{-2}(\mathrm{E}>0.1 \mathrm{MeV})$. The ILSS of the pure CE material drops by $\sim 20 \%$, whereas a reduction of $35 \%$ is found for the system containing $40 \% \mathrm{CE}$.

- A mixing ratio of $40 \% \mathrm{CE}$ and $60 \%$ turns out to be the best compromise between radiation resistance and costs, i.e. employing a relatively low amount of the far more expensive CE.

In a second step two materials supplied by European (Huntsman) and US (CTD) industry were tested under tension and interlaminar shear load prior to and after irradiation to twice the ITER design fluence in order to qualify them for ITER.

- The UTS of the unirradiated Huntsman and the CTD materials is $3029 \mathrm{MPa}$ and $360 \mathrm{MPa}$, respectively. After irradiation the UTS amounts to approximately $290 \mathrm{MPa}$ for both materials. Similar results are obtained under dynamic load. The S-N curves show a continuous decrease up to $10^{6}$ load cycles and are nearly identical 
for both materials. No distinct changes of the dynamic material performance were observed after irradiation. Regarding ITER, where 30000 load cycles are expected, the residual strength is about $130 \mathrm{MPa}$, which is more than adequate.

- The apparent ILSS of the unirradiated Huntsman and CTD materials is nearly the same and slightly above 70 MPa for $0^{\circ}$ and slightly below $60 \mathrm{MPa}$ for $90^{\circ}$ direction. After irradiation, the ILSS remains nearly unchanged for both materials in $0^{\circ}$ direction, and is slightly reduced by about $10 \%$ in $90^{\circ}$ direction to approximately $50 \mathrm{MPa}$.

Both the Huntsman and the CTD materials have demonstrated their high radiation resistance up to a radiation level, which will be accumulated over the ITER lifetime and beyond, i.e. at twice the ITER design fluence, and are therefore, fully qualified for the TF coil insulation.

\section{Acknowledgements}

We wish to thank Mr. A. Linzer and Mr. E. Tischler for technical assistance. The smooth cooperation with Huntsman and CTD as well as with Marti-Supratec is gratefully acknowledged.

\section{REFERENCES}

i For a more detailed discussion of the interaction of radiation with matter, see H. W. Weber, Radiation effects on superconducting fusion magnet materials, Int. J. Modern Physics E 20 (2011) 1325-1378
[1] K. BITTNER-ROHRHOFER, et al., Low temperature tensile strength of the ITER-TF model coil insulation system after reactor irradiation, Cryogenics 42 (2002) 265-272

[2] K. BITTNER-ROHRHOFER, et al., Mechanical behavior of the ITER TF model coil ground insulation system after reactor irradiation, Cryogenics 42 (2002) 697-704

[3] K. HUMER, et al., Radiation effects on the mechanical properties of insulators for fusion magnets, Fus. Eng. Des. 81 (2006) 2433-2441

[4] I. HAMERTON, et al., The development of novel functionalised aryl cyanate esters, part 2, mechanical properties of the polymers and composites, Polymer 42 (2001) 2307-2319

[5] K. BITTNER-ROHRHOFER, et al., Radiation hardness of newly developed ITER relevant insulation systems, Fus. Eng. Des. 66-68 (2003) 1209-1213

[6] K. BITTNER-ROHRHOFER, et al., Radiation effects on the mechanical integrity of novel organic insulators for the ITER magnet coils, J. Nucl. Mat. 329-333 (2004) 1083-1087

[7] M. HOOKER et al., Industrialization of radiation-resistant cyanate ester magnet insulation, IEEE Trans. Appl. Supercond. 19,3 (2009) $2367-2370$

[8] P. ROSENKRANZ, et al., Influence of the test geometry on the fatigue behavior of fiber reinforced plastics in tension and interlaminar shear at RT and $77 \mathrm{~K}$, Adv. Cryog. Eng.. 46 (2000) 181-187

[9] H.W. WEBER, et al., Neutron dosimetry and damage calculations for the TRIGA Mark-II reactor in Vienna, J. Nucl. Mat. 137 (1986) 236-240 